\title{
Arduino Based Dual Axis Solar Tracking System with Voltage and Temperature Measurement
}

\author{
Mayank Bajpai ${ }^{1}$, Piyush Saxena ${ }^{2}$ \\ Department of Instrumentation and Control NSIT Delhi \\ New Delhi, India \\ Email :_mayankshiv07@gmail.com ${ }^{1}$, piyushsaxena79@yahoo.com²
}

\begin{abstract}
This hardware device concept keeps the solar cells persistently aligned with the solar radiation, which maximizes solar panel sensitivity to the radiation from the sun. As a result, the solar panel will produce maximum output power. The use of solar trackers will increase the bearing of electricity by about a third and some people in some regions say as much as 40 percent compared to modules at a fixed angle. The project's work includes hardware design and implementation and programming software for the solar tracker microcontroller device. The system used an ATmega328P microcontroller to control two DC gear motors that rotate two axes of the solar panel. The microcontroller calculated the amount of rotation based on inputs from two LDR Sensors. The concept was prospering built and tested using Lab View to assess the performance enhancements.
\end{abstract}

Keywords: Tmega328P, DC gear motor, LDR Sensor, Temperature sensor, Arduino UNO.

\section{INTRODUCTION}

Sun is an excellent source of energy, and the use of solar photovoltaic cells and photovoltaic effect to turn power into electrical power will efficiently tackle this solar energy. This hardware technology has been widely adopted for commercial and residential use. Nowadays, we thanks to different organization and research teams that are working thoroughly to improve solar cell performance and reduce costs. The electrons in the silicon cells are produced electricity when excited using photons of light from the solar radiation. The paper proposes an inexpensive active double axis tracker based on a microcontroller. [1] With the aid of trackers, the panels are reoriented to the appropriate location. The sensor makes sure the panel is pointed toward the light.

Maximum energy is obtained as trackless orientation tends to shift during the day to match the sun's direction. [2] The sensors will activate the motor/actuator, which will cause the mounting device movement so that the solar panels will still be perpendicular to the sun all day long. [3] An Arduino uno, single-board microcontroller, dc gear motor, LDR sensor, and a voltage sensor and temperature sensor are used with LCD monitor to display the measured voltage and temperature value.

\section{II . System Specification}

There are many main components, i.e. LDR sensor, Arduino, Motor driver, dc gear motor, LCD, Temperature sensor. There is four LDR sensor which senses the intensity of light. [4] They follow the property of decreasing resistance with increasing the incident light intensity, i.e. the value of resistance of each value of LDR sensor is not the same. each LDR sensor sends a signal according to there respective resistance value to the Arduino, which is then processed through the microcontroller and configured by particular programming logic. [5] The microcontroller then sends a signal to the motor driver according to the signal received from the LDR sensor so that it can drive the DC gear motor.

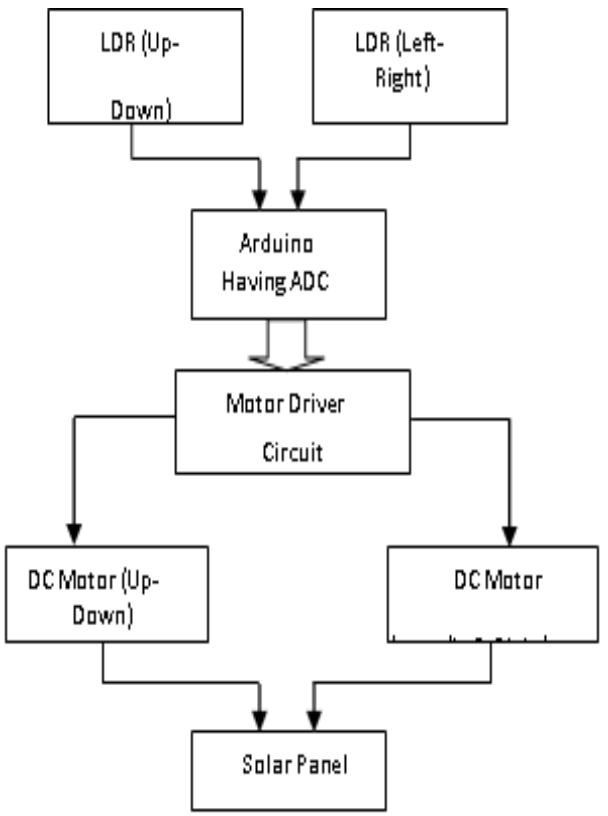

Fig 1: Block Diagram

There are several hardware components which are named in fig.1.Both hardware and software plays a vital role in determining the exact location of the solar tracker. So, a detail description of hardware components are shown below. 


\section{A. Solar Cell}

The photovoltaic cell is a non-mechanical silicon amalgam gadget. [6] It converts light energy received from the sun into electricity. Photovoltaic cluster designed depends on daylight. In street lighting, domestic use, industrial areas, the solar panel find its applications. Its efficiency is almost 10 to $20 \%$. Its rated power is $10 \mathrm{~W}$ and the rated voltage and current is $16.4 \mathrm{Vmp}$ and $0.61 \mathrm{Imp}$.

\section{B. LDR (Light Dependent Resistor)}

It runs on the concept of photoconductivity. Its resistance decreases as light intensity increases. [7] According to it, LDR is used to sense the light and provide an analog signal to Arduino. It is made up of semiconductor material having high resistance. When light (photons) incident on the device, the electrons in the semiconductor material's valence band jump to the conduction band, increasing the number of charge carriers. [8] Thus, the flow of current is increased, resulting in a decrease in resistance. The variation of resistance with incident light is non-linear. Therefore, they require calibration.

\section{Arduino Uno}

It is a microcontroller based on ATmega328.It is an open-source microcontroller developed by Arduino. [9] The UNO board is the first in a series of USB Arduino boards and the backing blueprint for the Arduino plan of action. The ATmega328p on the Arduino UNO comes pre-programmed with a boot loader that permits the transmission of new code to it without using an extrinsic instrument programmer. It passes on using the original STK500 protocol. [10] The communication between the STK500 and the PC is done over RS232 (PC COM PORT). The STK500 uses $115.2 \mathrm{kbps}, 8$ data bits, 1 stop bits and parity. It also consists of 6 analog pins and 14 digital pins. [11] It is programmable with the Arduino IDE via a type B USB cable. It can be powered by a USB cable or by an external $9 \mathrm{~V}$ battery, though it also accepts voltage between 7 and 20 volts. Its purpose is to control the position of the motor. Arduino's advantages are low cost, robust design and independent board. It has a clock speed of $16 \mathrm{MHz}$.

\section{Motor Driver}

The L293 and L293D devices are fourfold high1. Drivers, latch relay drivers, DC motor drivers etc. It mainly consists of $\mathrm{H}$-bridge circuits, which are frequently used in robotics. Due to this, the motor can run in both directions that is on both forward and backward. [12] It is also used to reverse the direction of the motor and also to break the motor. Its voltage range is between $4.5 \mathrm{~V}$ TO $36 \mathrm{~V}$. It has a separate input logic supply. Its input is unsusceptible to noise and internal protection is also provided. Its execution is in stepper motor

\section{DC gear Motor}

It is a dual shift plastic gear motor. [13] Its main advantage is to provide good operating Mounting body holes and lightweight making its deal for incircuit positioning torques and high rpm at very low operating voltages. Approximately equal to 100 RPM. Its output torque capability is $4 \mathrm{~kg}$-cm..Its operating voltages is between $3 \mathrm{~V}$ to $12 \mathrm{~V}$ and speed

\section{E. $L C D$}

LCD stands for liquid crystal display. It is an electronic module and are very thin and is composed of several layers. It has two polarized panels with a liquid crystal solution sandwiched between them. Light is projected through the layer and is colorized as it passes, thereby producing the visual image. The JHD162A LCD unit consists of 16 pins and can display 16x2 monochrome characters. Two lines of the display where each line can hold 16 characters. It can be interfaced in a 4-bit mode or an 8-bit mode. when an electric current is applied to the liquid crystal molecules, they untwist.

[14] A reflecting mirror is arranged at the back of the unit. An electrode plane is used to allow flow in selected areas. The entire arrangement is placed inside a sealed casing, with necessary electronics for controlling the device. The information that is displayed on the LCD is in ASCII form.

\section{F. Temperature Sensor}

In this hardware model a DHT11 temperature sensor is used. [15] It is essential humidity and temperature sensor of very low cost. Inside it, there is a capacitive humidity sensor and a thermistor to measure the encompassing air and gives a digital signal to the digital pin. It is simple to use. It is of low cost and its maximum current is approximately $2.5 \mathrm{~mA}$. [15] Its sampling rate is not more than 1 $\mathrm{Hz}$. Its temperature range is between 0 to 50 degrees Celsius with a temperature error of 2 degree Celsius.

\section{ALGORITHM}

Phase 1- Get the program started. Phase 2- Initialize the panel position. Phase 3Calculate the LDR resistance.

Phase 4- If the resistance of LDR $1<\mathrm{LDR} 2$ move the panel up.

Phase5- If the resistance of LDR1>LDR2 move the panel down.

Phase 6- if the resistance of LDR3<LDR4 move the panel left.

Phase 7- if the resistance of LDR3>LDR4 move 
the panel right.

Phase 8- if the resistance of LDR doesn't change.

Then the panel position remain as it is.

II.

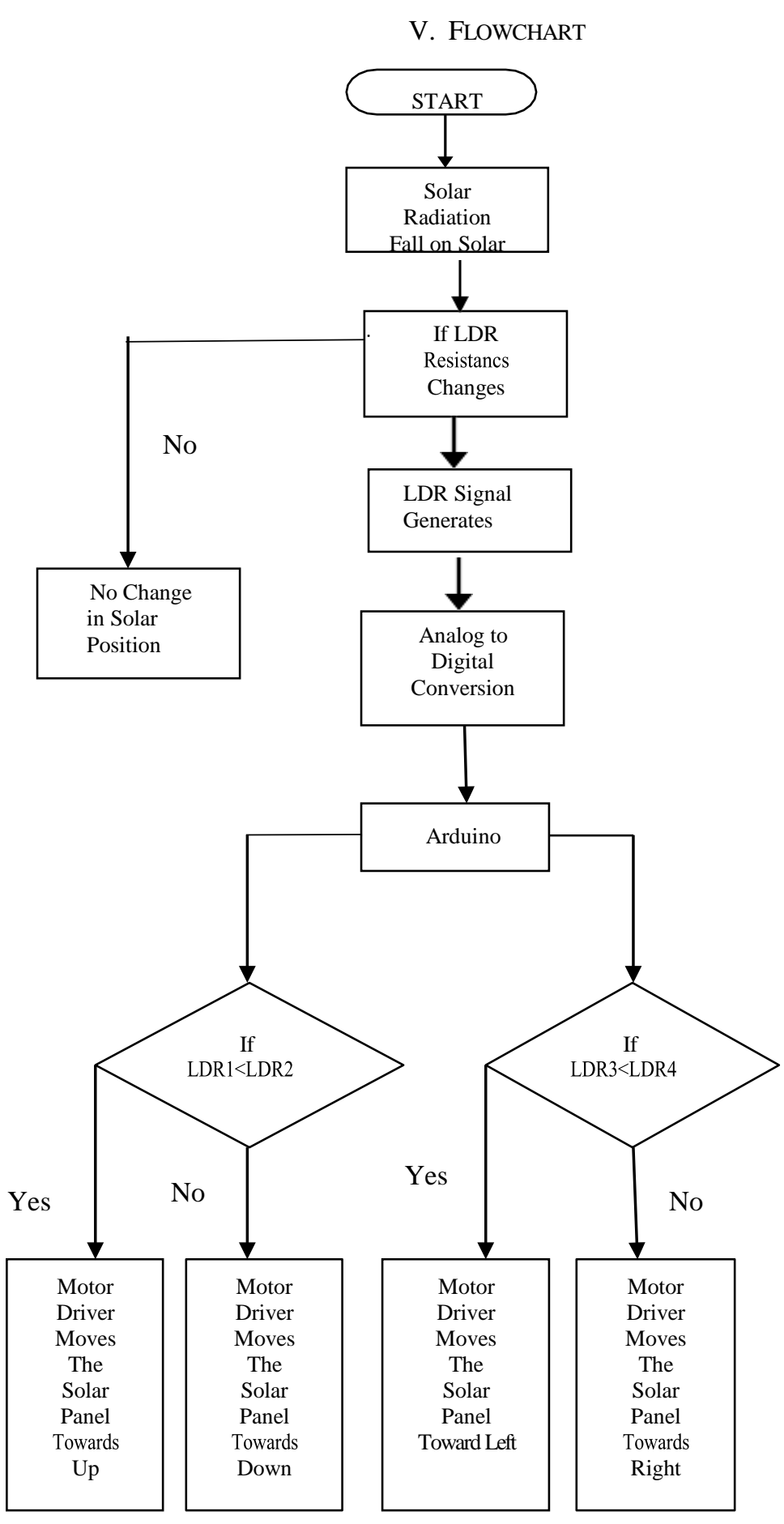

The above flowchart shows the working principle of a hardware model in a detailed form. It also shows how solar- panel achieve their position as solar radiation changes.

VI. Hardware Model

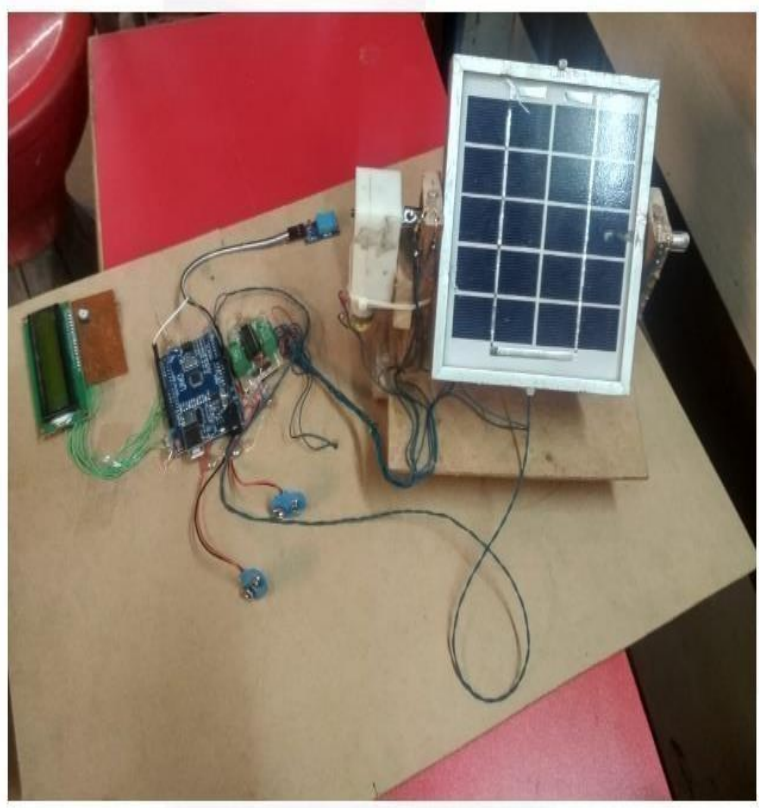

Fig.3 Hardware picture

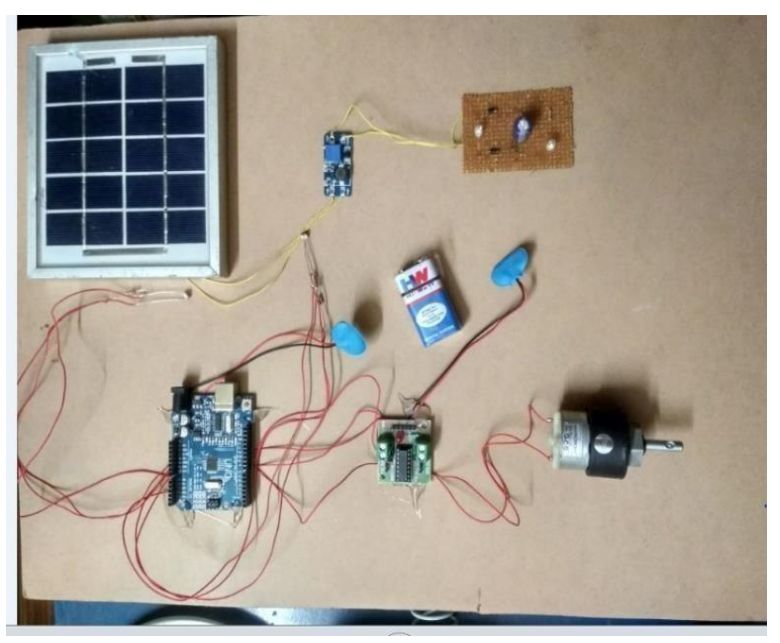

Fig.4 picture of different components that were used in hardware model. 


\section{VII . RESULTS}

The following results were obtained with the help of the hardware and software model. There is a table that shows the products at a different time and is thoroughly observed. The table shows the variation of voltage with and without tracking. There is also a temperature sensor that senses the temperature. The analysis was first made out on a fixed solar panel and then again through the movable solar panel with the dual axis solar tracker's help. The obtained results were displayed on the $16 \times 2$ LCD. The LCDs the measured voltage and current at different time. The analysis was also done on other days simultaneously, and the average results were shown in the table. The results were shown on the table described as shown.

\begin{tabular}{|c|c|c|c|}
\hline Time & $\begin{array}{l}\text { Voltage } \\
\text { without } \\
\text { tracking }\end{array}$ & $\begin{array}{l}\text { Voltage } \\
\text { with } \\
\text { tracking }\end{array}$ & $\begin{array}{l}\text { Temperature } \\
\text { degree Celsius }\end{array}$ \\
\hline $\mathbf{9 : 3 0} \mathbf{A M}$ & $2.35 \mathrm{~V}$ & $2.67 \mathrm{~V}$ & 20 \\
\hline $\mathbf{1 1 : 3 0}$ AM & $3.12 \mathrm{~V}$ & $4.14 \mathrm{~V}$ & 24 \\
\hline $\mathbf{1 : 3 0} \mathbf{~ P M}$ & $3.89 \mathrm{~V}$ & $6.13 \mathrm{~V}$ & 34 \\
\hline $\mathbf{3 : 3 0}$ PM & $3.36 \mathrm{~V}$ & $5.24 \mathrm{~V}$ & 29 \\
\hline $\mathbf{5 : 3 0}$ PM & $2.76 \mathrm{~V}$ & $3.86 \mathrm{~V}$ & 27 \\
\hline
\end{tabular}

\section{CONCLUSION}

In this hardware model, a dual axis solar tracker is implemented with the help of motor driver and arduino. It is more efficient than fixed system. It tracks the sunrays by moving the solar panel with the help of dc gear motor which is controlled by a motor driver circuit. The input pulse to the motor driver circuit is provided by arduino. LDR first senses the light intensity and produced signal according to its resistance value which goes to the arduino through ADC. The ADC converts the analog value of signal into digital. Then, arduino gives this signal to motor driver circuit and thus the motor driver circuit produces the signal which control the position of solar panel through dc motor. In this way the circuit works. It is very inexpensive and easy to implement. It operates automatically. There is also a temperature sensor which is used to sense the temperature. The experimental results are obtained. This model is also friendly in nature and are widely used.

\section{REFERENCE}

[1] Chin, C. S., Babu, A., \& McBride, W. (2011). Design, modeling and testing of a standalone single axis active solar tracker using
MATLAB/Simulink. Renewable Energy, 36(11), 3075-3090.

[2] Hua, C., \& Shen, C. (1998, February). Comparative study of peak power tracking techniques for solar storage system. In APEC'98 Thirteenth Annual Applied Power Electronics Conference and Exposition (Vol. 2, pp. 679685). IEEE.

[3] Grover, R., Krishnan, S., Shoup, T., \& Khanbaghi, M. (2014, March). A competitionbased approach for undergraduate mechatronics education using the arduino platform. In Fourth Interdisciplinary Engineering Design Education Conference (pp. 78-83). IEEE.

[4] Abas, M. A., Kadir, S. A., \& Azim, A. K. (2010, December). Improved structure of solar tracker with microcontroller based control. In 2010 in Second International Conference on Advances in Computing, Control, and Telecommunication Technologies (pp. 55-59). IEEE.

[5] Kaur, T., Mahajan, S., Verma, S., \& Gambhir, J. (2016, July). Arduino based low cost active dual axis solar tracker. In 2016 IEEE 1st International Conference on Power Electronics, Intelligent Control and Energy Systems (ICPEICES) (pp. 15). IEEE.

[6] Ulaganathan, M. K. D., Saravanan, C., \& Chitranjan, O. R. (2014). Cost-effective Perturb and Observe MPPT method using arduino microcontroller for a standalone photo voltaic system. International Journal of Engineering Trends and Technology (IJETT), 8(1), 24-28.

[7] Zolkapli, M., Al-Junid, S. A. M., Othman, Z., Manut, A., \& Zulkifli, M. M. (2013, June). Highefficiency dual-axis solar tracking developement using Arduino. In 2013 International Conference on Technology, Informatics, Management, Engineering and Environment (pp. 43-47). IEEE.

[8] Bentaher, H., Kaich, H., Ayadi, N., Hmouda, M. B., Maalej, A., \& Lemmer, U. (2014). A simple tracking system to monitor solar PV panels. Energy conversion and management, 78, 872-875.

[9] Ashi, A., Joudeh, A. A., Shafeey, M., Sababha, B. H., \& Istehkam, S. N. (2014, April). A PV solar tracking system: Design, implementation and algorithm evaluation. In 2014 5th International Conference on Information and Communication Systems (ICICS) (pp. 1-6). IEEE.

[10] Gabe, I. J., Bühler, A., Chesini, D., \& Frosi, F. (2017, April). Design and implementation of a low-cost dual-axes autonomous solar tracker. In 2017 IEEE 8th International Symposium on Power Electronics for Distributed Generation Systems (PEDG) (pp. 1-6). IEEE.

[11] Deep, A., Singh, J., Narayan, Y., Chatterji, S., \& Mathew, L. (2015, November). Robotic arm 
controlling using automated balancing platform. In 2015 Communication, Control and Intelligent Systems (CCIS) (pp. 282-285). IEEE.

[12] Priyadarshini, A., Dehury, N., \& Samantaray, A. K. (2015, September). A real time portable embedded system design for particulate matter monitoring. In 2015 IEEE Bombay Section Symposium (IBSS) (pp. 1-5). IEEE.

[13] Babu, T. G., \& Babu, G. A. (2020). Identification of Crop Health Condition Using IoT Based Automated System. In Advances in Data Science and Management (pp. 421-433). Springer, Singapore.

[14] Das, S., Sadhu, P., Pal, N., \& Mukherjee, S. (2014). Single Axis Automatic Solar Tracking System Using Microcontroller. TELKOMNIKA Indones. J. Electr. Eng, 12, 8028-8032.

[15] Chakraborty, S., Sadhu, P. K., \& Pal, N. (2015). Technical mapping of solar PV for ISM-an approach toward green campus. Energy Science \& Engineering, 3(3), 196-206. 